\title{
Experimental study of the effects of acid microemulsion flooding to enhancement of oil recovery in carbonate reservoirs
}

\author{
Tereza Neuma de Castro Dantas ${ }^{1} \cdot$ Andrey Costa de Oliveira $^{1} \cdot$ Tamyris Thaise Costa de Souza $^{2}$. \\ Cláudio Regis dos Santos Lucas ${ }^{3} \cdot$ Edson de Andrade Araújo $^{3}$. Pedro Tupã Pandava Aum ${ }^{3}$
}

Received: 1 May 2019 / Accepted: 2 August 2019 / Published online: 8 August 2019

(c) The Author(s) 2019

\begin{abstract}
Enhanced oil recovery (EOR) techniques play an essential role in the maintenance of petroleum production worldwide. These techniques are receiving special attention due to the continuous decline in availability of oil resources. The study of surfactants and correlated systems have been considered due to their capacity to alter the wettability and interfacial proprieties, consequently reducing residual oil saturation and increasing oil production. In this context, heterogeneity becomes one of the main challenges to overcome, for it makes the fluid flow preferably thought the highest permeability regions, affecting sweep efficiency. It is also known that acids react with carbonate formations promoting matrix dissolution. However, few works in the literature report the use of reactive fluids in EOR. Therefore, this work analyzes the effects of reactive acid flow on porous carbonate media and its impact on advanced oil recovery operations. It presents an experimental study of the effects of acid microemulsion flooding in the enhancement of oil recovery in carbonate reservoirs. Acid microemulsions studied were characterized by surface tension, droplet diameter, viscosity, and corrosiveness. Flooding experiments demonstrated that the reactive flow of acid microemulsions in porous media increases oil recovery, achieving up to $30 \%$ additional recovery of the total oil in place. However, by increasing the reactivity of the systems, severe dissolution of the porous matrix can occur. The results presented open a new path on the use of low reactive fluids in enhanced oil recovery.
\end{abstract}

Keywords Surfactant $\cdot$ Acid microemulsion $\cdot$ EOR $\cdot$ Reactive flow $\cdot$ Reservoir

\section{Introduction}

Fossil fuels represent the primary energy source currently in use. To meet international oil demand, it is necessary to enhance the oil production of existing oil fields. Hydrocarbon exploration involves three stages of recovery (primary, secondary, and tertiary) also known as enhanced oil recovery (EOR). Due to the combination of effects such as capillarity pressure, rock heterogeneity, and wettability, the natural reservoir energy can usually produce up to $15 \%$ of the initial oil in place. The secondary oil recovery consists of the injection

Tereza Neuma de Castro Dantas

tereza@eq.ufrn.br

1 Chemical Institute, Federal University of Rio Grande Do Norte, Natal, Brazil

2 Geosciences and Engineering Institute, Federal University of Southern and Southeastern of Pará, Marabá, Brazil

3 School of Petroleum Engineering, Federal University of Pará, Salinópolis, Brazil of gas or water in the reservoir, and can lead up to a $30 \%$ increase in oil-in-place recovery. Therefore, considering that conventional methods of primary and secondary recovery can produce only less than one-half of the original oil in place, enhanced recovery methods play an essential role in the recovery of additional oil from the reservoir (Mothé et al. 2006; Malik et al. 2016; Tunnish et al. 2017).

The financial impact of the recovery is even more significant in the case of giant oil fields, such as those found in the Brazilian offshore reservoirs. The increase of only $1 \%$ in the total percentage of oil-in-place recovery could represent more than one billion oil barrels, making oil companies interested in applying more advanced recovery methods to maximize oil recovery.

Throughout EOR methods, chemical flooding techniques, including polymer flooding, alkaline flooding, and flooding of surfactant systems, have been reported as a promising techniques based on experimental laboratory studies and field work (Liu et al. 2004; Benzagouta et al. 2013; Castro Dantas et al. 2017). 
The use of surfactants in the EOR reduces interfacial tensions between injected fluid and the oil, increasing oil volume sweep (Nazar et al. 2011). The use of microemulsions in surfactant systems have been considered a promising technique for EOR. A major challenge in advanced oil recovery processes is found in carbonate formations, which contain nearly $50 \%$ of the world's known hydrocarbon resources. Carbonate formations are generally oil-wettable. In these scenarios, the use of microemulsions has been studied to act both on capillary effects and on wettability of the carbonate surface (Castro Dantas et al. 2014).

Another great challenge presented by carbonate formations is their heterogeneity. The same formation can present zones of high and very low permeability. In turn, it can isolate zones with high oil content reducing the volume sweep. Several works studied surfactant systems applied to EOR processes (Santanna et al. 2013; Bera and Mandal 2015; Najafi et al. 2017; Nguele et al. 2017; Torrealba and Hoteit 2018; Torrealba et al. 2018). One important parameter that has impact on the volume swept is the viscosity of the displacing fluid. In case of microemulsions obtained with ionic surfactants, works demonstrate the viscosity increasing due salinity changes into reservoir's thieves zones which diverge subsequent treatment to higher oil saturation zones. The increase in viscosity takes place when ionic surfactants solutions and a brine with a previous determined concentration are mixed into reservoir or the temperature changes modifying microemulsion's microstructure from globular to rod-like micelles (Torrealba and Hoteit 2018; Torrealba et al 2018). However, when using acid systems, the rheology is low affected by the salinity. This can assure the stability of these systems when in the presence of high acid concentrations. Although the use of microemulsions to EOR is discussed in literature, few studies report the use of reactive systems applied to advanced oil recovery. Therefore, this work proposes to study the effects of reactive acid flow on porous carbonate media and its impact on the advanced oil recovery operations. Generally, the use of reactive flow is present only in production enhancement of well operations (Hoefner and Fogler 1985; Fredd et al. 1996, 2017; Aum et al. 2016; Dantas et al. 2019). However, this work studies the use of low reactive microemulsion systems capable of reducing acid-rock reactivity and optimizing advanced recovery from the injector well.

\section{Methodology}

\section{Materials}

To obtain pseudo-ternary diagrams, the following components were used: Alkonat L90 (nonionic surfactant) from Oxiteno; $n$-butanol (co-surfactant) from Vetec Química; kerosene (oil phase) from Petrobras; and acid solution of $\mathrm{HCl}$ (aqueous phase) at different concentrations $(1.5,5,10$, and $15 \% \mathrm{wt} / \mathrm{wt})$.

\section{Development of pseudo-ternary phase diagrams- determination of microemulsion regions}

Phase behavior study was performed to investigate the ability of surfactant to form microemulsions in the presence of an acid phase. The (liquid-liquid) phase equilibrium was measured in ternary systems (surfactant + co-surfactant/oil phase/acid aqueous phase). The pseudo-ternary phase diagrams were constructed using the aqueous titration method which includes a stepwise addition of aqueous phase to each weight ratio of oil and active matter (surfactant + co-surfactant) followed by mixing of the components with the help of vortex at $25^{\circ} \mathrm{C}$. The phase equilibrium was verified by visual inspection and classified according to Winsor (1948). Winsor IV (WIV) represents a single-phase microemulsion and Winsor I (WI) represents the microemulsion equilibrium with an oil phase in excess.

\section{Rheology measurements}

The viscosity of the microemulsion middle phase was measured using an Anton Paar rheometer (MCR 302, Austria). The effects of acid concentration on the rheological properties of the microemulsion system were studied in the range of shear rate of 5 to $300 \mathrm{~s}^{-1}$.

\section{Droplet size and surface tension measurements}

Mean size diameter (nm) and polydispersity index were measured by dynamic light scattering in a particle size analyzer Zeta Plus equipment (Brookhaven Instruments). Sensadyne bubble tensiometer (QC 6000) was used to measure the surface tension of microemulsion systems at different acid concentrations.

\section{Potentiodynamic polarization curves}

The corrosivity of the systems was evaluated by obtaining experimental polarization curves. The experiments were performed in a potentiostat coupled to an electrolytic (Autolab PGSTAT 302N). In the electrolytic cell, where the electrodes are installed, the chemical reactions are processed. AISI 1018 steel was used for this work. Scanning was performed at speeds of 10 and $25 \mathrm{mV} / \mathrm{s}$. The potential range varied from -0.5000 to $+0.005 \mathrm{mV}$, i.e., $0.5000 \mathrm{mV}$ for the anode band and $0.0005 \mathrm{mV}$ for the cathode band. For each evaluated condition, at least two polarization curves were obtained to ensure the reproducibility of the results. The reduction in corrosiveness provided by the microemulsion 
media was calculated using Eq. 1, where CIE (\%) is the corrosion inhibition efficiency, and $i_{\text {corr, }}$ and $i_{\text {corr }, 0}$ are the corrosion currents in the microemulsion and aqueous medium, respectively.

$\mathrm{CIE}(\%)=\frac{i_{\text {corr }, \mathrm{I}}-i_{\text {corr }, 0}}{i_{\text {corr,I }}}$

\section{Dissolution of calcium carbonate in nanoemulsion media}

Carbonate rocks are composed mainly of limestone $\left(\mathrm{CaCO}_{3}\right)$ and dolomite $\left(\mathrm{CaMg}\left(\mathrm{CO}_{3}\right)_{2}\right)$, which react with hydrochloric acid $(\mathrm{HCl})$ forming $\mathrm{CO}_{2}, \mathrm{H}_{2} \mathrm{O}$, and calcium or magnesium chloride. To evaluate the retardation of calcite dissolution owing to the microemulsion media, the consumption of calcium carbonate was correlated to the pressure increase over time during the reaction in a confined cell with constant stirring (Aum et al. 2016; Carvalho et al. 2019; Bulgakova et al. 2013). Equations (2) and (3) represent the acid dissolution of calcium carbonate and dolomite, respectively.

$$
\begin{aligned}
& \mathrm{CaCO}_{3}+2 \mathrm{HCl} \rightarrow \mathrm{CaCl}_{2}+\mathrm{H}_{2} \mathrm{O}+\mathrm{CO}_{2} \uparrow \\
& \mathrm{CaMg}\left(\mathrm{CO}_{3}\right)_{2}+4 \mathrm{HCl} \rightarrow \mathrm{CaCl}_{2}+\mathrm{MgCl}_{2}+2 \mathrm{H}_{2} \mathrm{O}+2 \mathrm{CO}_{2} \uparrow
\end{aligned}
$$

The increase in pressure is a consequence of $\mathrm{CO}_{2}$ release, as shown on the right side of Eqs. (2) and (3).

\section{Core flooding experiments}

To evaluate the performance of acid microemulsions prepared with a nonionic surfactant, a crude oil recovery experiment was conducted in the core-flood system, as depicted in Fig. 1. The experiments were carried out at $30{ }^{\circ} \mathrm{C}$ under $2000 \mathrm{psi}$ of overburden pressure in the core cell and 1100 psi of back pressure. Injection of the acid systems into the core was performed at a constant volumetric pumping rate. The core plugs, used in the flooding experiments, were prepared with $3.4 \mathrm{~cm}$ of diameter and $5.0 \mathrm{~cm}$ of length. The limestones used in the core-flood experiments were from the Jandaíra formation, an outcrop from a Northeast Brazilian Region. Initially, the saturation stage was carried out by injecting brine $(\mathrm{KCl} 20,000 \mathrm{ppm})$ at $1 \mathrm{ml} / \mathrm{min}$. In the sequence, the core plug was saturated with oil from the Ubarana-RN-Brazil field (API 33) at $1 \mathrm{ml} / \mathrm{min}$. A minimum of 8 pore volumes $(8 \mathrm{Vp})$ of each fluid was injected. After this process, the initial oil saturation was determined. The recovery study was divided into conventional and advanced recovery phases. Conventional recovery was performed by injecting the brine into the plug ( $3 \mathrm{Vp}$ ), followed by the advanced recovery where the acid microemulsion system $(3 \mathrm{Vp}$ ) was injected into the plug, at a flow rate of $1 \mathrm{ml} / \mathrm{min}$. After conventional and advanced recovery stages, the recovery efficiency was determined by quantifying the amount of accumulated oil produced after each stage.

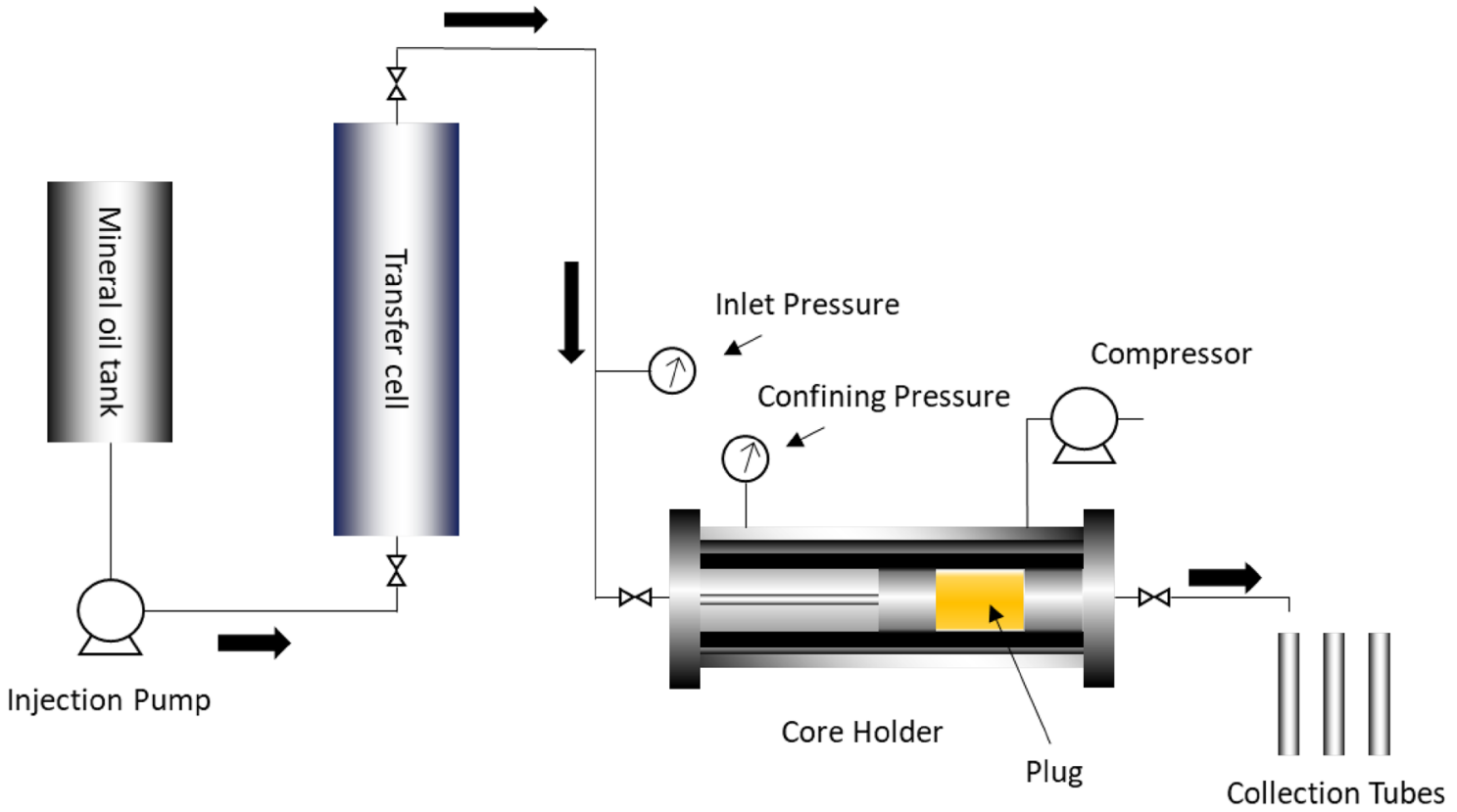

Fig. 1 Experimental reservoir simulator setup 


\section{Results and Discussion}

The results of this investigation will be discussed in three major parts. The first section will analyze the phase behavior and the characterization of the microemulsion systems studied. The second part addresses the dissolution kinetics of carbonate formations, focusing on the study of the retarded effect promoted by the microemulsified media. The third section reports the summary of the EOR core flooding experiments.

\section{Microemulsion Characterization}

Pseudo-ternary phase diagrams of microemulsion systems using nonionic surfactant (ALKONAT-L90), $n$-butanol, kerosene, and acid solutions were constructed in the combined diagram, as shown in Fig. 2. Results indicate that, for the system studied, the phase behavior of the pseudo-ternary phase diagram of the microemulsion system was not affected by acid concentration.

The concentration of the acid in the aqueous phase did not affect significantly the area size of the microemulsion region. The ratio of co-surfactant to surfactant $(\mathrm{CS} / \mathrm{S})$ was kept constant at 1:2. A composition with a low amount of surfactant, low oil concentration, and rich in water was chosen from the economic and-environment-friendly point of view for its use in oil recovery applications. In this case, the composition was chosen near aqueous apex on the overlapping pseudo-ternary diagram $(0.120 \mathrm{~g} / \mathrm{g}$ Alkonat L90, $0.06 \mathrm{~g} / \mathrm{g} n$-butanol, $0.020 \mathrm{~g} / \mathrm{g}$ kerosene, and $0.800 \mathrm{~g} / \mathrm{g} \mathrm{HCl}$ solution) varying only the concentration of acid within the system to be used during the recovery process.

Figure 3 shows the plots for the surface tension as a function of the surfactant concentration in the microemulsion media. Although microemulsion cannot be characterized in

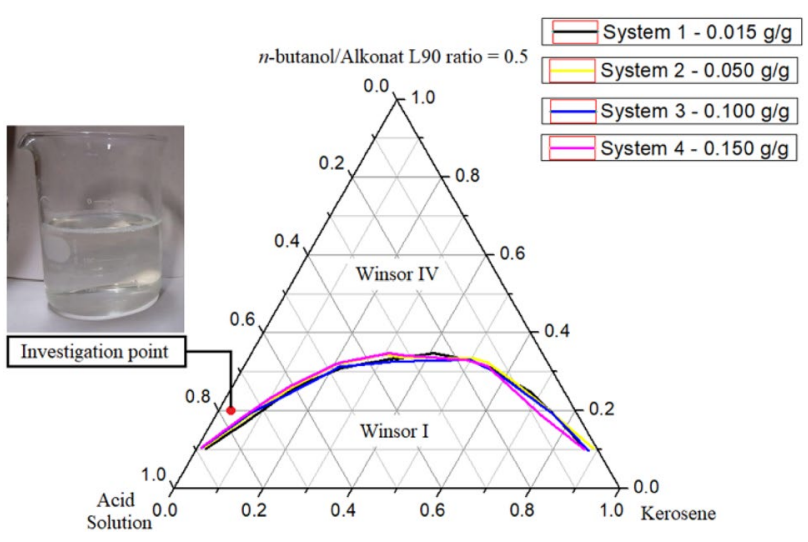

Fig. 2 Pseudo-ternary diagrams of the microemulsion systems with different $\mathrm{HCl}$ terms of a CMC value, we have detected variation in the values of surface tension for mixtures prepared with different surfactant contents. The tension continuously decreases with an increase in surfactant concentration, as expected.

Results demonstrate that low surface tension could be maintained in the acid microemulsion media until a concentration near $0.1 \%$ of surfactant for the systems studied.

The results of droplet size show that the systems obtained are inside the range of droplet size characteristic of the microemulsions, that is, below $200 \mathrm{~nm}$ (Ferreira et al. 2018). The polydispersity index values were above 0.3 , which is characteristic of monodisperse systems.

Figure 4 shows polarization curves at various acid concentration. We verified that, for all systems, the corrosiveness was reduced in the microemulsified medium. The corrosion inhibition promoted by the microemulsion media was up to $67 \%$.

The corrosiveness reduction promoted by the microemulsion media is remarkable, since many of the equipments used in the exploration and production petroleum are made out of metals, and the use of less corrosive fluids reduces equipment corrosion and reduces the cost of corrosion inhibitors.

Table 1 shows a summary of the results obtained by SFT, Ds, PDI, and CIE (corrosion inhibition efficiency) analysis of the microemulsion systems studied. One can observe that SFT, Ds, and PDI values of the microemulsion systems are similar, corroborating the understudying that the acid does not affect significantly the microemulsion structure formed by nonionic surfactant.

Rheological analyses of systems were performed by varying the acid concentration in the aqueous phase to understand the variation of viscosity against shear rate, as shown in Fig. 5. As observed, the viscosity maintains a constant path near $4 \mathrm{cP}$ indicating the Newtonian behavior of acid microemulsion systems.

Although the results reveal that an increase in acid concentration promotes a slight increase in viscosity, the values are still low and characteristic of microemulsions. The rheology of colloidal systems is affected strongly by the aggregate structure. Therefore, the results of viscosity, droplet size diameter, and polydispersity indicate that the micelles have a spherical shape.

\section{Reaction kinetics}

The results of dissolution kinetics are reported in Fig. 6 . The plots show pressure curves as a function of time for all four microemulsion systems, compared to their respective acid solutions in the aqueous medium. We observed that, for all acid concentrations, the dissolution reaction of calcite is retarded when compared with the reaction in the aqueous medium. Although the two curves in each graph show the 


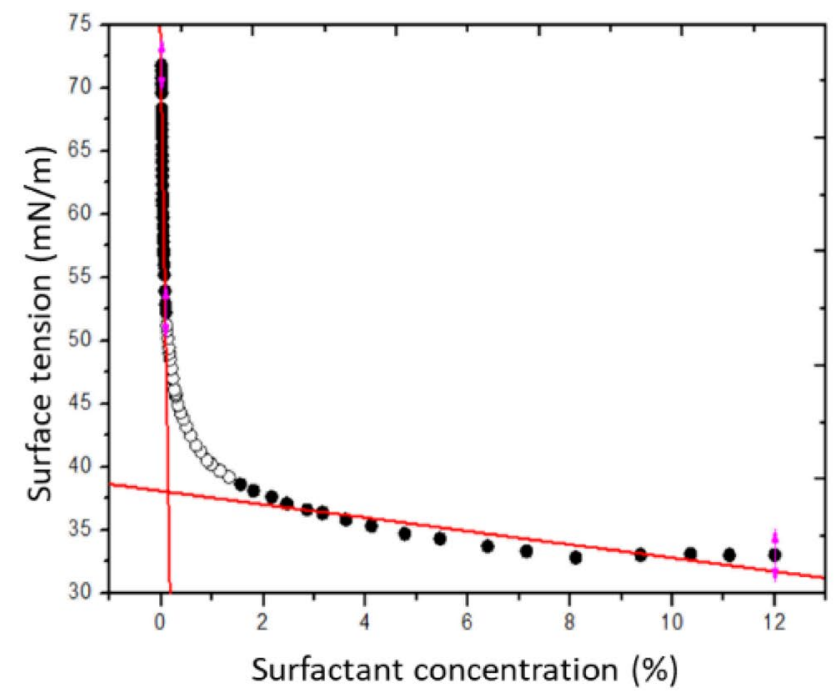

(a)

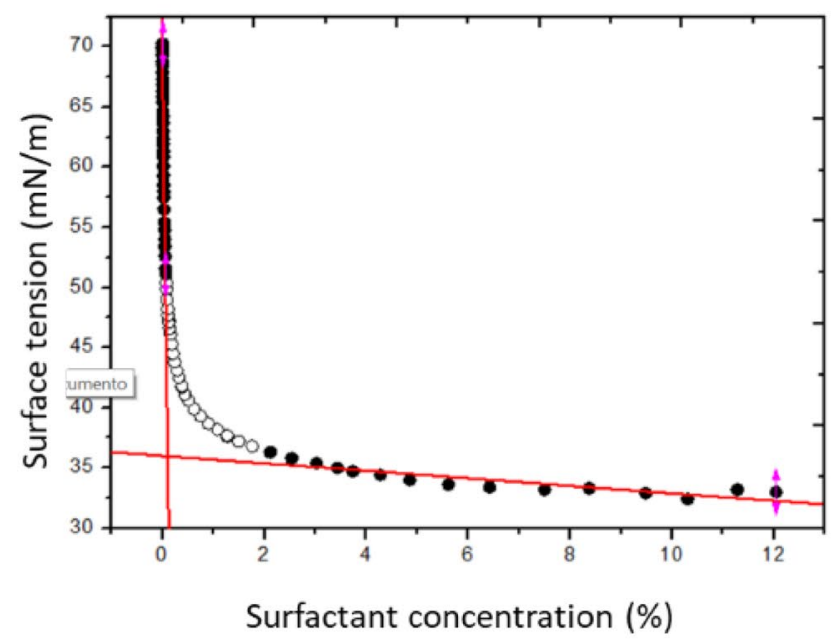

(c)

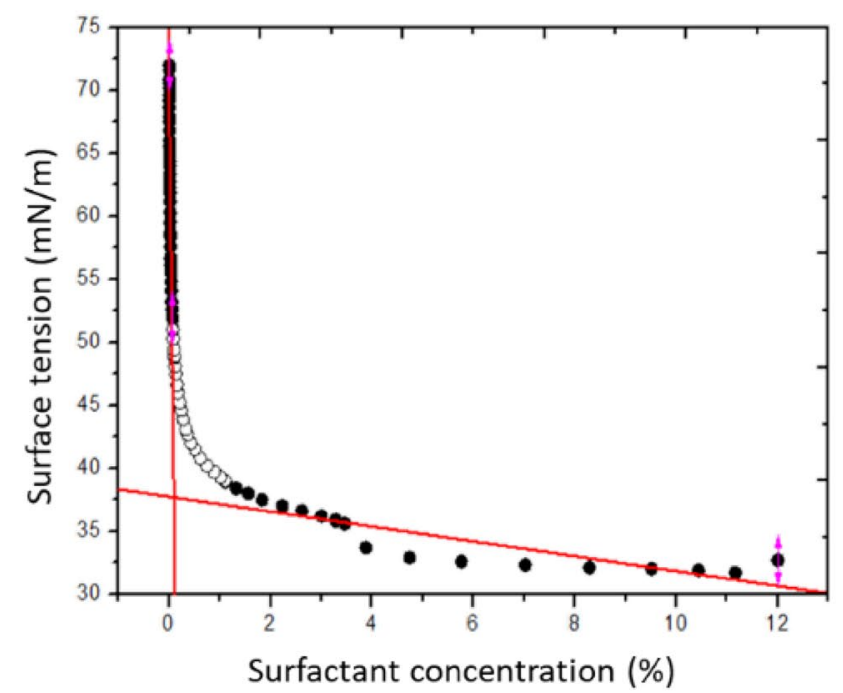

(b)

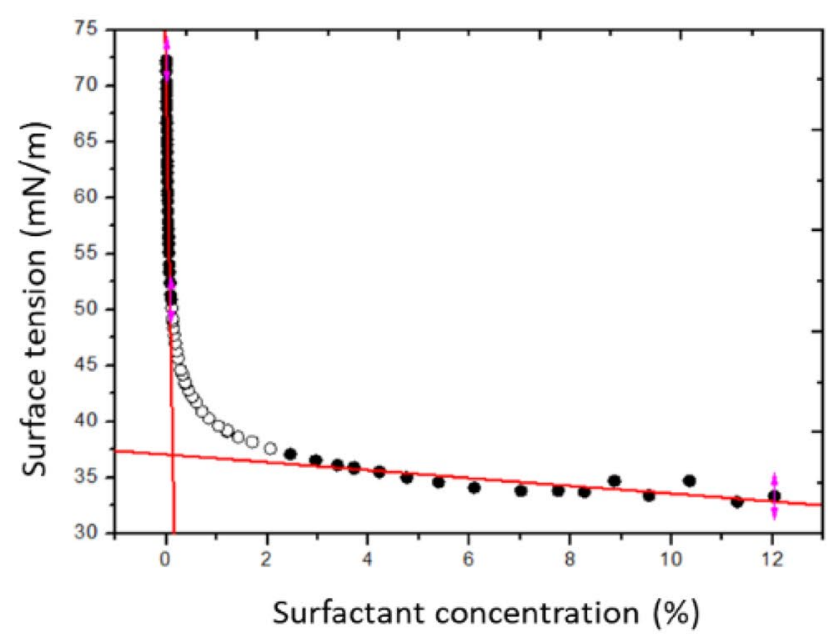

(d)

Fig. 3 Curves of surface tension versus surfactant concentration for the microemulsions in acid concentrations of a $1.5 \%$, b $5 \%$, c $10 \%$, and d $15 \%$

same concentrations of acid, they have different behaviors in a time interval of $30 \mathrm{~min}$.

All reactions performed in microemulsion media reached lower pressures at the same interval of time, demonstrating the ability of microemulsion system to retard the reaction of the acid with the rock. This happened because once the surfactant forms a direct micelle (oil-in-water- $\mathrm{O} / \mathrm{W}$ ), the $\mathrm{H}^{+}$present in the continuous phase tends to be attracted to the hydroxyl group present in the polar part of the surfactant, thereby reducing the interaction of $\mathrm{HCl}$ with the rock and lowering the reaction rate between them. Another factor is the adsorption of the microemulsion droplets in the rock's surface protecting the rock surface and, consequently, retarding the reaction.

\section{Core flooding experiments}

The results of oil recovery obtained during core flooding experiments are presented in Table 2, where Swi and Soi represent initial water and oil saturation, respectively. Table 2 shows the recovery factors for water, acid microemulsion flooding, and total recovery.

The initial oil saturation was in the range of $69-73 \%$. The water recovery factor (WRF) represents the percentage of the oil in place recovered after the water flooding stage. The WRF was in the range of 32-39\%. The difference between values are related to plug heterogeneity characteristic of carbonate formations. The injection of the acid microemulsions resulted in an additional oil recovery of $23-30 \%$. 


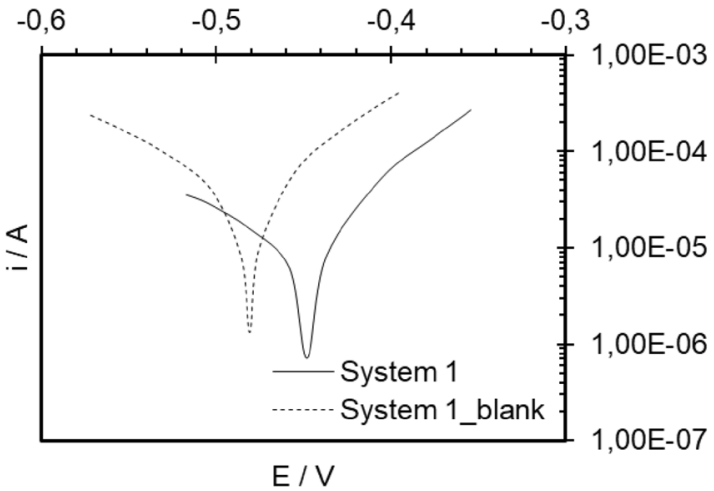

(a)

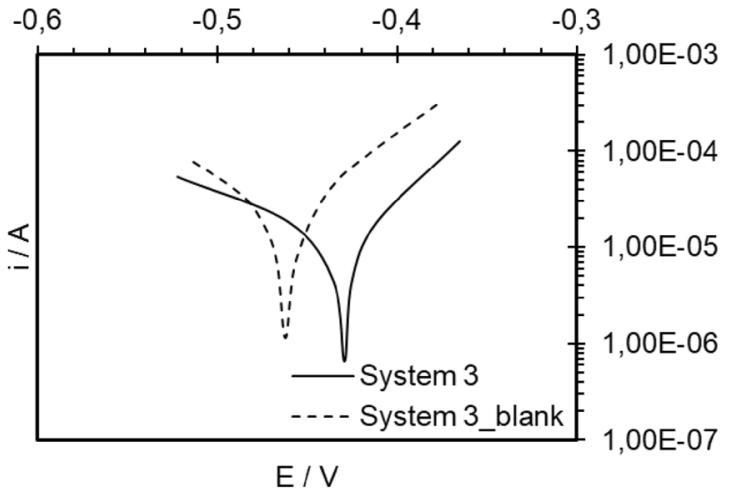

(c)

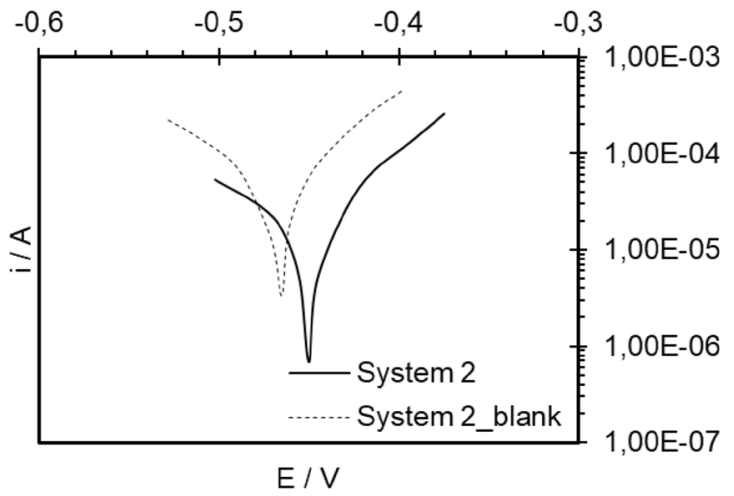

(b)

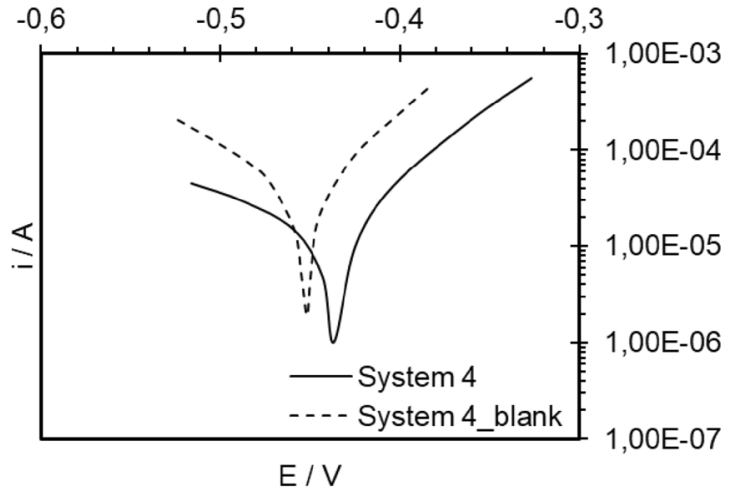

(d)

Fig. 4 Potential-kinetic polarization curves for carbon-steel in the presence of aqueous and microemulsified media with $\mathrm{HCl}$ in concentrations of: a $1.5 \%, \mathbf{b} 5 \%$, c $10 \%$, and $\mathbf{d} 15 \%$

Table 1 Acid microemulsion characterization

\begin{tabular}{lllll}
\hline System & SFT $(\mathrm{mN} / \mathrm{m})$ & Dd $(\mathrm{nm})$ & PDI & CIE $(\%)$ \\
\hline 1 & 33.0 & 142.6 & 0.535 & 66.3 \\
2 & 32.7 & 149.8 & 0.472 & 60.8 \\
3 & 33.0 & 164.6 & 0.301 & 67.3 \\
4 & 33.3 & 146.3 & 0.505 & 65.6 \\
\hline
\end{tabular}

For plugs I, II, and III we could observe an increase in the recovery factor with the increase in acid concentration. Plug IV shows a reduction in the increasing path, and the percentage of oil recovery by the acid microemulsion with $15 \% \mathrm{HCl}$ was $25 \%$. The results of the recovery factor for the acid microemulsion systems injected are plotted in the graph of Fig. 7. The graph shows recovery factor curves as a function of pore volume injected. One must also account for some effects to understand the results of the recovery curves obtained. First, the acid system reacts with the carbonate formation. The acid concentration has a positive relationship with the rock's consumption. Rock dissolution can help to connect isolated zones and increase the permeability of

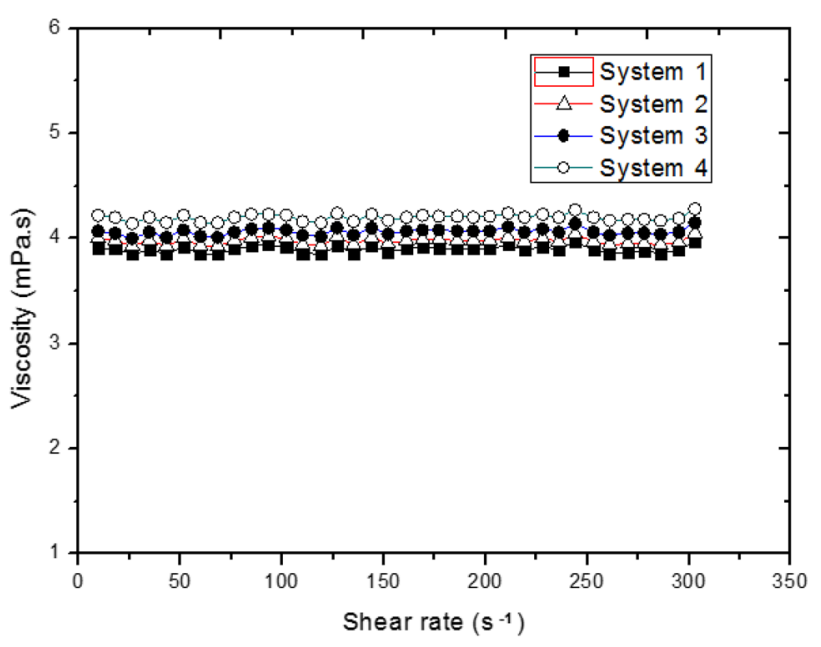

Fig. 5 Viscosity as a function of shear rate of microemulsion systems

low permeability zones. This effect helps increase sweep oil efficiency, increasing oil recovery. At the same time, the fluid-rock reaction can create a preferable channel, and form wormholes and left zones with oil without treatment. 


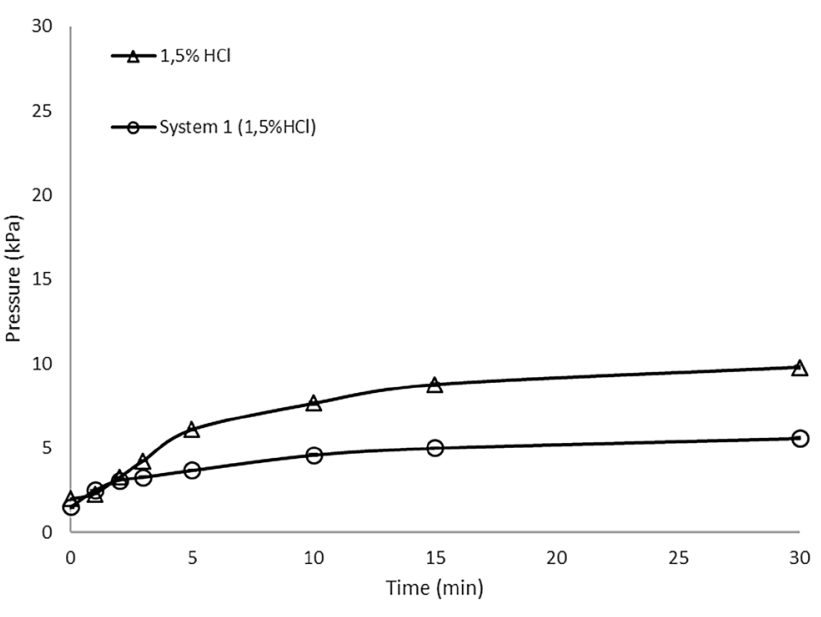

(a)

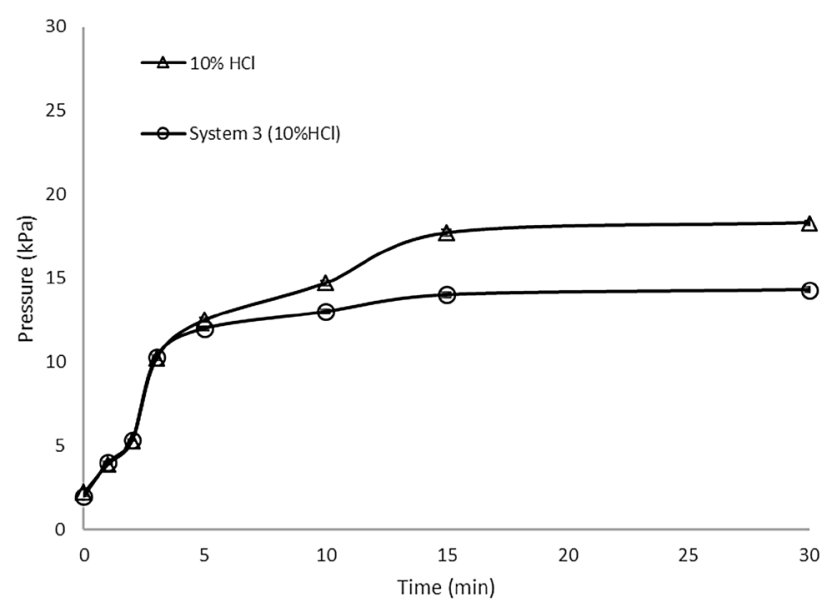

(c)

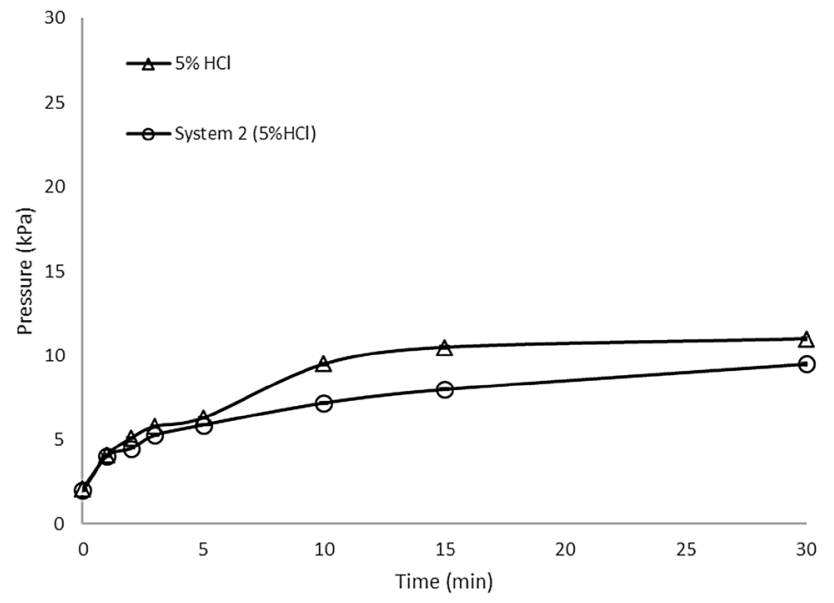

(b)

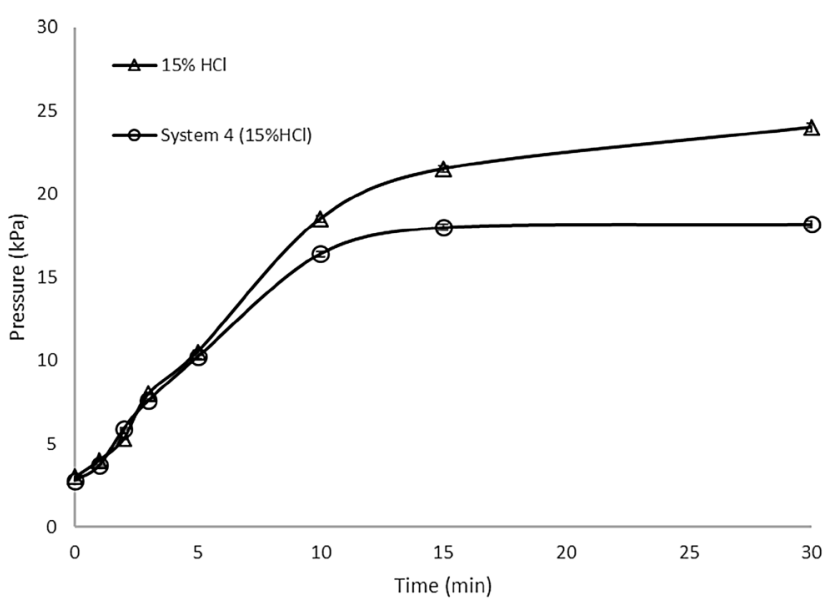

(d)

Fig. 6 Curves of pressure versus time for the dissolution reaction of calcium carbonate in acid systems and aqueous media

Table 2 Results of recovery tests with acid microemulsion systems

\begin{tabular}{lllll}
\hline Characteristic & \multicolumn{4}{l}{ Microemulsion system } \\
\cline { 2 - 5 } & 1 & 2 & 3 & 4 \\
& Plug & & & \\
\cline { 2 - 5 } & I & II & III & IV \\
\hline Initial porosity (\%) & 36.3 & 37.3 & 37.0 & 34.7 \\
Swi (\%) & 28 & 31 & 32 & 27 \\
Soi (\%) & 72 & 69 & 68 & 73 \\
Water recovery factor-WRF (\%) & 35 & 35 & 32 & 39 \\
Acid microemulsion recovery fac- & 23 & 26 & 30 & 25 \\
$\quad$ tor-AMRF (\%) & & & & \\
Total recovery factor-TRF (\%) & 58 & 61 & 62 & 63 \\
\hline
\end{tabular}

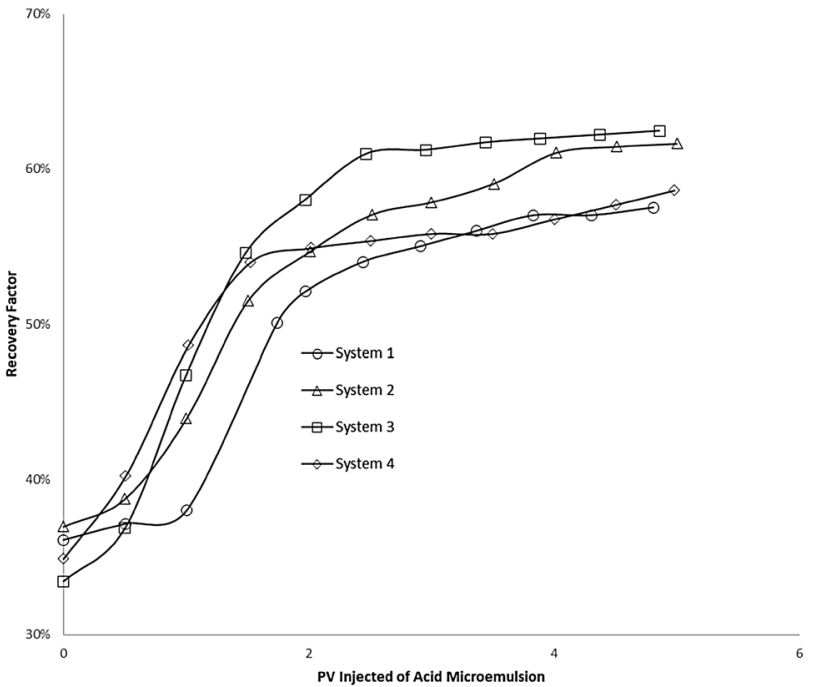

Fig. 7 Curves of recovery factor as a function of PV injected of acid microemulsion 
(a)

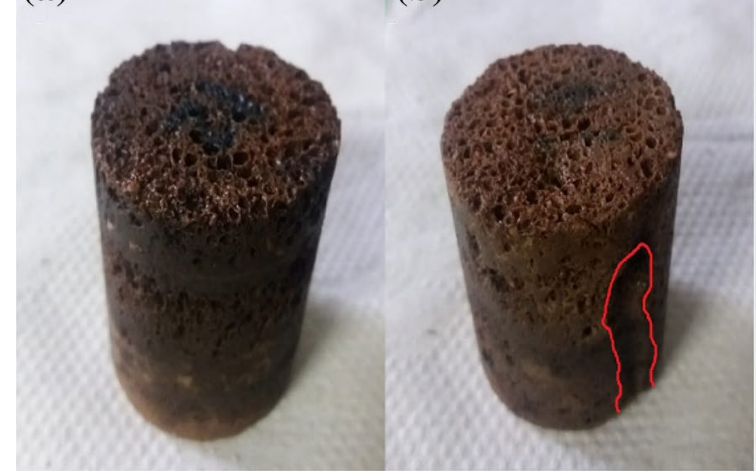

(c)

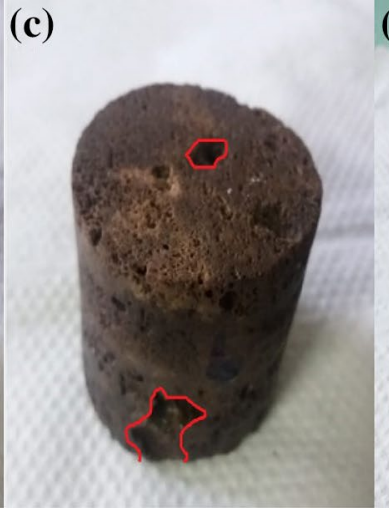

(d)

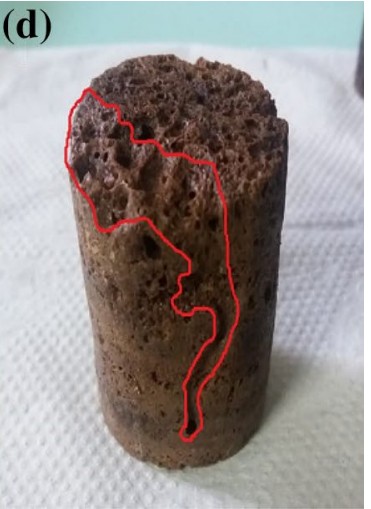

Fig. 8 Plugs after reaction with microemulsion with $\mathrm{HCl}$ in concentrations of: a 1.5\% (plug I), b 5\% (plug II), c 10\% (plug III), and d 15\% (plug IV)

This effect reduces the sweep efficiency decreasing the oil recovery. Therefore, we found a limit in where increasing the reactivity of the system helps to increase the recovery factor. Figure 8 shows the core plugs after the acid microemulsion treatment.

It is possible to observe that microemulsion systems with higher acid concentrations tend to present greater consumption matrix, leading to the formation of channels and altering flow patterns.

Although severe matrix dissolution is not desired in the reservoir perspective, our results demonstrate that a low reactive acidic system with retarded kinetics could be useful to reduce the residual oil saturation and, possibly, interconnect oil zones previously isolated. This concept could be a new pathway in the development of EOR systems.

\section{Conclusion}

Based on the experimental study developed, the following conclusions can be drawn:

1. Microemulsion systems studied could be obtained at different acid concentration with low variation of the proprieties evaluated, indicating that the acid weakly influences the nonionic surfactant arrangement (Alkonat L90).

2. $\mathrm{HCl}$ in microemulsion media is less corrosive than that in aqueous medium. The corrosion inhibition promoted by the microemulsion media was up to $67 \%$.

3. The microemulsion media can retard the dissolution reaction of rock in $\mathrm{HCl}$.

4. The use of acid microemulsions in EOR processes increase oil recovery efficiency. However, when a high concentration of $\mathrm{HCl}$ is used in aqueous solutions, several matrix dissolutions occurs, and the treatment do not collaborate to volume sweep efficiency anymore as a consequence of high-permeability channels formed.

Open Access This article is distributed under the terms of the Creative Commons Attribution 4.0 International License (http://creativeco mmons.org/licenses/by/4.0/), which permits unrestricted use, distribution, and reproduction in any medium, provided you give appropriate credit to the original author(s) and the source, provide a link to the Creative Commons license, and indicate if changes were made.

\section{References}

Aum PTP, Souza TN, Pereira YK, Aum G, de Castro Dantas TN, Neto AAD (2016) New acid o/w microemulsion systems for application in carbonate acidizing. Int J Adv Sci Technol Res 1:182-196

Bera A, Mandal A (2015) Microemulsions: a novel approach to enhanced oil recovery: a review. J Pet Explor Prod Technol 5(3):255-268

Benzagouta MS, AlNashef IM, Karnanda W, Al-Khidir K (2013) Ionic liquids as novel surfactants for potential use in enhanced oil recovery. Korean J Chem Eng 30(11):21

Bulgakova GT, Kharisov RY, Pestrikov AV, Sharifullin AR (2013) Experimental study of a viscoelastic surfactant-based in situ selfdiverting acid system: results and interpretation. Energy Fuels 28(3):1674-1685

Carvalho RT, Oliveira PF, Palermo LC, Ferreira AA, Mansur CR (2019) Prospective acid microemulsions development for matrix acidizing petroleum reservoirs. Fuel 238:75-85.08-2117

Castro Dantas TN, Soares APJ, Wanderley Neto AO, Dantas Neto AA, Barros Neto EL (2014) Implementing new microemulsion systems in wettability inversion and oil recovery from carbonate reservoirs. Energy Fuels 28(11):6749-6759

Castro Dantas TN, de Souza TTC, Dantas Neto AA, Moura MCPDA, de Barros Neto EL (2017) Experimental study of nanofluids applied in EOR processes. J Surfactants Deterg 20(5):1095-1104

Dantas TNC, Santanna V, Souza T, Lucas CRS, Neto AD, Aum PTP (2019) Microemulsions and nanoemulsions applied to well stimulation and enhanced oil recovery (EOR). Braz J Pet Gas 12(4):251 
Ferreira GFD, Souza DRQ, Lima R, Lobato AKCL, Silva ACM, Santos LCL (2018) Novel glycerin-based microemulsion formulation for enhanced oil recovery. J Pet Sci Eng 167:674-681

Fredd C, Fogler HS et al (1996) Alternative stimulation fluids and their impact on carbonate acidizing. In: SPE formation damage control symposium. Society of Petroleum Engineers

Fredd CN, Hoefner ML, Fogler HS (2017) Microemulsion applications in carbonate reservoir stimulation. In: Properties and uses of microemulsions. InTech

Hoefner M, Fogler H (1985) Effective matrix acidizing in carbonates using microemulsions. Chem Eng Prog (United States) 81(5):40-44

Liu Q, Dong M, Zhou W, Ayub M, Zhang YP, Huang S (2004) Improved oil recovery by adsorption-desorption in chemical flooding. J Pet Sci Eng 43(1-2):75-86

Malik IA, Al-Mubaiyedh UA, Sultan AS, Kamal MS, Hussein IA (2016) Rheological and thermal properties of novel surfactantpolymer systems for EOR applications. Can J Chem Eng 94(9):1693-1699

Mothé CG, Correia DZ, De Franca FP, Riga AT (2006) Thermal and rheological study of polysaccharides for enhanced oil recovery. $\mathrm{J}$ Therm Anal Calorim 85(1):31-36

Nazar MF, Shah SS, Khosa MA (2011) Microemulsions in enhanced oil recovery: a review. Pet Sci Technol 29(13):1353-1365

Najafi SAS, Kamranfar P, Madani M, Shadadeh M, Jamialahmadi $M$ (2017) Experimental and theoretical investigation of CTAB microemulsion viscosity in the chemical enhanced oil recovery process. J Mol Liq 232:382-389

Nguele R, Sasaki K, Sugai Y, Al-Salim HS, Ueda R (2017) Mobilization and displacement of heavy oil by cationic microemulsions in different sandstone formations. J Pet Sci Eng 157:1115-1129

Santanna VC, Silva ACM, Lopes HM, Neto FS (2013) Microemulsion flow in porous medium for enhanced oil recovery. J Pet Sci Eng 105:116-120

Torrealba VA, Hoteit H (2018) Conformance improvement in oil reservoirs by use of microemulsions. SPE Reservoir Evaluation \& Engineering

Torrealba VA, Hoteit H, Johns RT (2018) Description of micellar radii for phase behavior and viscosity modeling of aqueous surfactant solutions and microemulsions. Langmuir 34(50):15327-15334

Tunnish A, Shirif E, Henni A (2017) Enhanced heavy oil recovery using 1-ethyl-3-methyl-imidazolium acetate. Can J Chem Eng 95(5):871-879

Winsor PA (1948) Hydrotropy, solubilisation and related emulsification processes. Trans Faraday Soc 44:376-398

Publisher's Note Springer Nature remains neutral with regard to jurisdictional claims in published maps and institutional affiliations. 